\title{
Colistín en infecciones nosocomiales por bacilos gramnegativos pan-resistentes
}

\author{
Alberto Fica C., Ignacio Céspedes J., Macarena Gompertz G., \\ Mauricio Jalón V., Andrea Sakurada Z. y Enzo Sáez L.
}

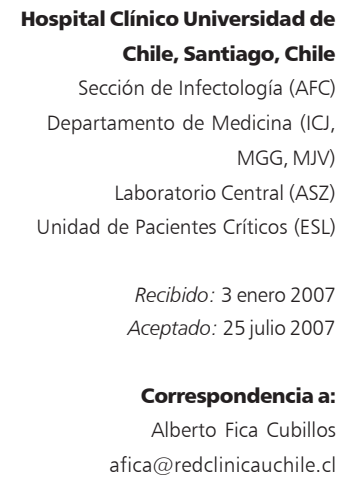

,

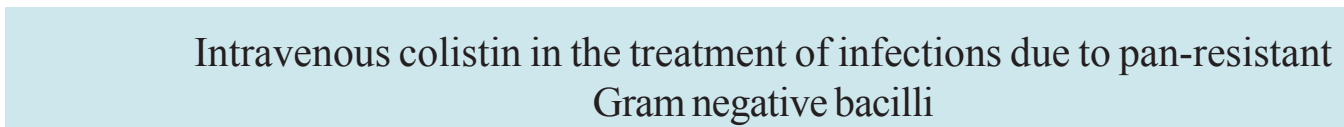

Emergence of panresistant gram negative bacilli has lead to the progressive reintroduction of intravenous colistin. Aim: To describe the clinical experience observed with this compound. Methodology: A retrospective analysis was performed for all treatments lasting $>48$ hours. Medical records were analyzed to obtain clinical parameters and microbiological data, evaluate clinical response and evolution until discharge. Main results: 24 treatments lasting $>48$ hours were applied between June 2005 and September 2006. Intravenous colistin was indicated to treat cases of ventilator-associated (VA) pneumonia $(n=10 ; 41.7 \%)$, abscess or collections $(12.5 \%)$, bloodstream infections, non-VA pneumonia or urinary tract infections ( $4.2 \%$ each one, respectively). Treatment was initiated on average at 3.2 days $( \pm 2.85)$ from diagnosis of infection. All courses were microbiologically-guided, and involved $P$. aeruginosa or A. baumannii isolates. Susceptibility was evaluated by E-test in 11 isolates ( $\mathrm{MIC}_{90} 3.6 \mu \mathrm{g} / \mathrm{mL}$, range 0.38 to $4 \mu \mathrm{g} / \mathrm{mL}$ ). One isolate was resistant to colistin $(9 \%)$. A favorable response was observed in 12 treatments $(50 \%)$ with a relapse in 5 cases $(41.7 \%)$. Being treated for pneumonia was the only factor associated to failure. $(p=0.04)$ Eradication was documented in 8 cases $(33.3 \%)$ and persistence in $11(45.8 \%)$. In 5 cases a microbiological follow-up was not available. Survival at time of discharge was $45.5 \%$. $(\mathrm{n}=10)$ None of the treatment courses was associated with nefrotoxicity. Conclusions: Intravenous colistin is a safe compound useful to treat various nosocomial infections due to pan-resistant gram negative bacilli. Nonetheless, its clinical efficacy is limited, especially among patients treated for nosocomial pneumonia.

Key words: colistin, sepsis, Gram negative bacilli, panresistance.

Palabras claves: colistín, bacilos gramnegativos, infecciones, pan-resistencia.

\section{Introducción}

$\mathrm{L}$ as infecciones nosocomiales son un problema frecuente y se asocian a morbilidad, aumento de los costos y letalidad atribuible. Están asociadas a microorganismos multi o pan-resistentes que limitan, seriamente, las posibilidades de mejoría clínica y obligan a utilizar costosos antimicrobianos.

Ocupan un lugar central en estas infecciones los bacilos gramnegativos del tipo enterobacterias y bacilos gramnegativos no fermentadores como Pseudomonas aeruginosa y Acinetobacter baumannii; estos últimos, se caracterizan por un mayor perfil de multiresistencia y, numerosas veces, como bacterias panresistentes, es decir, sin alternativas registradas para su manejo. El ámbito de infecciones por estos microorganismos es relevante, ya que participan en bacteriemias, neumonía asociada a ventilación mecánica, infección del sitio quirúrgico o infecciones del SNC, asociadas a drenajes ventriculares.
Los datos epidemiológicos sobre la frecuencia de bacilos gramnegativos multi o pan-resistentes son escasos en el país, debido a que sólo recientemente se ha creado un sistema de vigilancia activo. Se trata, sin embargo, de un hecho progresivo radicado, especialmente, en las unidades de cuidados intensivos de hospitales de la Región Metropolitana. En el Hospital Clínico de la Universidad de Chile, la frecuencia de aislados de $A$. baumannii o $P$. aeruginosa pan-resistentes ha aumentado en forma constante desde el año 2004, motivando la importación de colistín para el manejo de estas infecciones.

Colistín endovenoso es un fármaco de alto costo, no exento de toxicidad renal y carece de una evaluación rigurosa de su eficacia clínica. Por ejemplo, el costo diario de tratamiento con este antimicrobiano supera los 60 mil pesos chilenos (aproximadamente 120 U\$). Habitualmente, los pacientes son tratados por 10 o más días. 
El objetivo de esta publicación es presentar los resultados obtenidos en una serie clínica de pacientes tratados con este compuesto y analizar factores potenciales que influyen en la respuesta.

\section{Pacientes y Métodos}

Criterios de inclusión. Se incluyeron todos aquellos pacientes que presentaron infecciones por bacilos gramnegativos multi o pan-resistentes y en los que se utilizó colistín endovenoso, durante al menos 48 horas, desde junio de 2005 (primer caso tratado en el hospital) y hasta septiembre de 2006. Se incluyeron sólo pacientes en los que se trató una infección acompañada de síntomas y signos atribuibles.

Definiciones. Se consideró multi-resistente a aquella cepa con resistencia a cefalosporinas de tercera generación (con o sin inhibidores de $\beta$-lactamasa), quinolonas, algún aminoglucósido o carbapenémicos. Las cepas pan-resistentes fueron definidas como aquellas resistentes a todos los compuestos contenidos en el estudio de susceptibilidad, exceptuando el colistín.

Durante el período de estudio no se evaluó la susceptibilidad a tigeciclina ni estuvo disponible para tratamientos.

Variables clínicas y de laboratorio. Se registraron los datos biodemográficos de los pacientes, antecedentes mórbidos, cirugías experimentadas en los últimos 12 meses, fecha de ingreso, traslado desde otros centros o reingreso al hospital, fecha de diagnóstico de la infección en la que se utilizó colistín, datos microbiológicos, antibiograma, incluyendo susceptibilidad a colistín por E-test (si estaba disponible). Se consideró como nivel de corte para resistencia a colistín una CIM $>2 \mu \mathrm{g} / \mathrm{mL}$, de acuerdo con el criterio de la Sociedad Francesa de Microbiología ${ }^{1,2}$. También se evaluó la puntuación APACHE II (Acute Physiological Chronic Health Evaluation) $)^{3}$ al momento del ingreso a la UCI y la presencia de hemodiálisis o shock al comienzo del tratamiento. Asimismo, se registró si durante el uso de colistín se utilizaron otros compuestos con actividad sinérgica contra este tipo de bacterias, tales como rifampicina, amikacina y carbapenémicos ${ }^{4,5}$. Los sitios de infección fueron catalogados como bacteriemia, neumonía asociada a ventilación mecánica (VM) o no asociada a VM, colección o infección del sitio quirúrgico, infección urinaria asociada a catéter urinario o como infección múltiple.

Compuesto y dosis. Todos los pacientes fueron tratados con colistín, disponible en frascos de polvo liofilizado de 1.000 .000 de UI, equivalentes a $80 \mathrm{mg}$ de colistimetato sódico (Forest Laboratorios, Kent, Reino Unido). Los pacientes fueron tratados con rangos de dosis diarias entre 2 y $5 \mathrm{mg} / \mathrm{kg}$ de peso. En caso de falla renal, las dosis fueron ajustadas de acuerdo con el siguiente esquema: para valores de filtración glomerular de 30 a $50 \mathrm{~mL} / \mathrm{min}: 2,5 \mathrm{mg} / \mathrm{kg} /$ día; para valores entre 10 y $30 \mathrm{~mL} / \mathrm{min}: 1,5 \mathrm{mg} / \mathrm{kg} /$ día y para cifras $<10 \mathrm{~mL} / \mathrm{min}: 1$ $\mathrm{mg} / \mathrm{kg}$ cada 1 ó 2 días.

Evaluación de la respuesta clínica y microbiológica. La respuesta al tratamiento fue catalogada como favorable si se observó una mejoría clínica y de laboratorio durante el uso del colistín y como fracaso si el paciente falleció durante el tratamiento o permaneció en condiciones clínicas estacionarias. Además, se evaluó la mortalidad hasta el egreso hospitalario. La respuesta microbiológica fue catalogada como erradicación, si en el mismo sitio del cultivo original, un cultivo posterior al tratamiento demostró la ausencia del bacilo resistente. En caso de que el primer cultivo posterior al término del tratamiento, demostrara la presencia del bacilo inicial, se asignó la respuesta como persistencia. Aquellos casos en los cuales no hubo cultivo de seguimiento, la respuesta microbiológica fue asignada como no evaluable. Se consideró también la existencia de un tratamiento combinado cuando colistín fue usado en forma concomitante con rifampicina, carbapenémicos o aminoglucósidos.

Evaluación de nefrotoxicidad. En este trabajo se utilizaron los mismos criterios considerados por otros autores para definir nefrotoxicidad ${ }^{6}$. Para aquellos pacientes con función renal previa normal, se definió como el incremento de la concentración de creatininemia en $2 \mathrm{mg} / \mathrm{dL}$ durante el uso de colistín. Para pacientes con función renal previa anormal, se consideró como nefrotoxicidad, el aumento al doble de la creatininemia inicial. Se registró también, el uso concomitante de fármacos nefrotóxicos (vancomicina, ciclosporina, aminoglucósidos, anfotericina B deoxicolato).

Análisis estadístico. Se aplicó la prueba del $\chi^{2}$ para el análisis de potenciales factores asociados a una mala respuesta al tratamiento. Estos factores incluyeron la edad, co-morbilidad, el sitio de la infección, la presencia de múltiples sitios de infección, la gravedad al ingreso a la UCI (APACHE II), la oportunidad del tratamiento, la dosis diaria de colistín por kilo de peso y el uso de terapia combinada. Las variables continuas (puntuación Apache II, edad, etc) fueron transformadas en variables categóricas para este tipo de análisis. 
Tabla 1. Características generales de los pacientes tratados con colistín ev

\begin{tabular}{lcc} 
Condición & Frecuencia o valor promedio & Porcentaje o rango \\
\hline Edad años & 58,2 & $16-88$ \\
\hline Sexo (M/F) & $9 / 13$ & $40,9 / 59,1 \%$ \\
\hline Uso previo antimicrobianos & 22 & $100 \%$ \\
VM > 48 horas & 19 & $82,6 \%$ \\
\hline IIH previa & 16 & $69,6 \%$ \\
\hline Neoplasia & 7 & $31,8 \%$ \\
\hline Diálisis al inicio & 6 & $25 \%$ \\
\hline Insuficiencia renal crónica & 5 & $22,7 \%$ \\
\hline Cirugía último año & 5 & $22,7 \%$ \\
\hline Diabetes mellitus & 2 & $9,1 \%$ \\
\hline Insuficiencia cardíaca & 2 & $9,1 \%$ \\
\hline Trasplante & 2 & $9,1 \%$ \\
\hline Shock presente al inicio & 2 & $8,3 \%$ \\
Evento vascular & 1 & $4,5 \%$ \\
\hline APACHE II al ingreso a UCl & & \\
\hline $0-9$ & 1 & $5 \%$ \\
\hline $10-19$ & 11 & $55 \%$ \\
\hline $20-29$ & 4 & $20 \%$ \\
\hline$\geq 30$ & 4 & $20 \%$ \\
\hline Subtotal con APACHE II & 20 & \\
\hline VM: Ventilación mecánica & & \\
\hline
\end{tabular}

\begin{tabular}{|lcc|}
\hline \multicolumn{4}{c}{ Tabla 2. Infecciones tratadas con colistín ev } \\
\hline Condición & $\mathbf{n}$ & $\%$ \\
\hline Neumonía asociada a VM & 10 & 41,7 \\
Bacilos gramnegativos resistentes en múltiples sitios & 8 & 33,3 \\
Colección o absceso & 3 & 12,5 \\
Bacteriemia & 1 & 4,2 \\
Neumonía no asociada a VM & 1 & 4,2 \\
\hline Infección urinaria asociada a catéter urinario & 1 & 4,2 \\
\hline Total & 24 & 100 \\
\hline VM: Ventilación mecánica & & \\
\hline
\end{tabular}

Tabla 3. Características del tratamiento y de la susceptibilidad ante colistín

\begin{tabular}{lcc} 
Componente & Valor promedio o frecuencia & SD o \% \\
Oportunidad de tratamiento & 3,2 días & 2,85 \\
Duración tratamiento & 12 días & 5 \\
\hline Dosis en pacientes sin diálisis & $3,24 \mathrm{mg} / \mathrm{Kg} . /$ día & 0,88 \\
Dosis en pacientes en diálisis & $1,13 \mathrm{mg} / \mathrm{Kg} . /$ día & 0,75 \\
Tratamiento combinado & 20 cursos & 83,3 \\
$\begin{array}{l}\text { Susceptibilidad a colistín } \\
\mathrm{CIM}(\mu \mathrm{g} / \mathrm{mL}) \\
\mathrm{CIM}\end{array}$ & $0,38-4$ \\
Resistencia, $\mathrm{n} / \mathrm{total}(\%)$ & $1,0-3,6$ & \\
\hline
\end{tabular}

\section{Resultados}

Características generales de la población. Un total de 24 tratamientos en 22 pacientes fue identificado en los 16 meses del período bajo análisis. La edad promedio de los pacientes fue de 58,2 años (rango 16 a 88 años) con un leve predominio de pacientes de sexo femenino $(n=13 ; 59,1 \%)$. Casi un tercio de los pacientes $(31,8 \%)$ presentaba neoplasias, $22,7 \%$ insuficiencia renal crónica y $22,7 \%$ había sido intervenido quirúrgicamente en los últimos 12 meses (Tabla 1). Otras condiciones co-mórbidas fueron infrecuentes en la población estudiada (diabetes mellitus, insuficiencia cardíaca, trasplante o evento vascular cerebral) (Tabla 1). El promedio (DS) de la puntuación APACHE II para los 20 pacientes que ingresaron a la UCI fue de 20,45 puntos ( $\pm 8,7$, rango 7 a 37 puntos). Cuarenta por ciento de los pacientes tenía un puntaje $\geq 20$ (Tabla 1).

Infecciones tratadas con colistín. Este fármaco fue utilizado, mayoritariamente, en eventos de neumonía asociada a VM $(\mathrm{n}=10 ; 41,7 \%)$. Otras indicaciones incluyeron colecciones o abscesos $(12,5 \%)$, bacteriemias, neumonía no asociada a $\mathrm{VM}$ e infección urinaria (4,2\% cada una, respectivamente). En términos globales, más de la mitad de los casos $(\mathrm{n}=14 ; 58,3 \%)$ tenía varios focos de infección y en ocho de ellos se utilizó colistín para el tratamiento de bacilos gramnegativos pan-resistentes en diferentes sitios $(33,3 \%)$ (Tabla 2). La terapia se inició con un promedio (DS) de 3,2 días ( $\pm 2,85$, rango 0 a 12$)$ desde el diagnóstico de la infección (Tabla 3). La duración promedio (DS) del tratamiento fue de $12 \pm 5$ días (rango 5 a 28 días). La dosis promedio utilizada en paciente sin diálisis fue de 3,24 $\pm 0,88 \mathrm{mg} / \mathrm{kg}$ de colistín al día y en aquellos con diálisis fue de $1,13 \pm 0,75 \mathrm{mg} / \mathrm{kg}$ /día (Tabla 3). La infección que motivó el tratamiento con este compuesto se presentó en promedio (SD) 39 días $\pm 27,3$ días después del ingreso (rango 10 a 122 días). Veinticinco por ciento de los pacientes tenían terapia dialítica al inicio del tratamiento con colistín. Sólo dos pacientes presentaban shock al inicio de este tratamiento $(8,3 \%)$ (Tabla 1). Todos los pacientes habían recibido antimicrobianos previamente y casi $70 \%$ había presentado una infección nosocomial con anterioridad (Tabla 1). La mayoría de los pacientes recibió un tratamiento combinado con otro antimicrobiano, ya fuera rifampicina, aminoglucósidos o carbapenémicos $(n=20$; $83,3 \%$ ) (Tabla 3). La combinación mayoritaria fue con carbapenémicos $(\mathrm{n}=16 ; 66,7 \%)$.

Datos microbiológicos. Todos los casos contaban con información microbiológica sobre el sitio de infec- 
ción que justificó el uso de colistín: $P$. aeruginosa o $A$. baumannii. En total, se identificaron 30 aislados de estas dos especies provenientes de 16 casos de infecciones de un solo órgano o sitio anatómico $(53,3 \%)$ y en los restantes $(\mathrm{n}=14 ; 46,7 \%)$, desde múltiples focos de infección. Los aislados de $P$. aeruginosa fueron predominantes, representando $63,3 \%(\mathrm{n}=19)$ del total. Acinetobacter baumannii se asoció, con mayor frecuencia, a múltiples sitios de infección, en comparación a $P$. aeruginosa; 9 de 11 cepas de esta especie estuvieron asociadas a infecciones múltiples versus 5 de 19 aislados de $P$. aeruginosa ( $\mathrm{p}=0,003$ por la prueba de $\chi^{2}$ ). En ocho casos hubo otros microorganismos asociados a alguna de estas dos especies y correspondieron a: bacilos gramnegativos entéricos en un caso, cocos grampositivos en cuatro y otros microorganismos en tres casos.

Con una excepción, todas las cepas de $P$. aeruginosa y $A$. baumannii presentaron un perfil pan-resistente. La excepción la constituyó un tratamiento de un paciente con una colección abdominal por $P$. aeruginosa sólo sensible a amikacina, y en el cual se prefirió no utilizar esta alternativa.

Se pudo contar con el estudio de susceptibilidad para colistín por E-test en 11 aislados. El rango de CIM fue de 0,38 a $4 \mu \mathrm{g} / \mathrm{mL}$ y los valores de $\mathrm{CIM}_{50}$ y $\mathrm{CIM}_{90}$ fueron $1 \mu \mathrm{g} / \mathrm{mL}$ y $3,6 \mu \mathrm{g} / \mathrm{mL}$, respectivamente. Sólo una cepa presentó un valor de CIM en el rango considerado resistente $(4 \mu \mathrm{g} / \mathrm{mL})$, la que correspondió a un caso de infección abdominal por $P$. aeruginosa, en concomitancia con una infección pulmonar por Staphylococcus aureus y Stenotrophomonas maltophilia. La paciente falleció.

Respuesta al tratamiento y búsqueda de factores asociados. La respuesta al tratamiento fue catalogada como favorable en la mitad de los casos $(n=12 ; 50 \%)$. En cinco de los 12 tratamientos en los cuales se observó una respuesta favorable, se observó una recaída clínica de la infección $(41,7 \%)$. En ocho casos se logró la erradicación del microorganismo bajo tratamiento $(33,3 \%)$ y en 11 casos se documentó la persistencia del agente causal en el mismo sitio al finalizar el tratamiento $(45,8 \%)$. En cinco casos $(20,8 \%)$, el resultado microbiológico no fue evaluable. En tres de los cinco casos en los cuales se observó una recaída de la infección clínica, se observó persistencia del agente, pero ello no fue estadísticamente significativo.

Una búsqueda de potenciales factores ligados al fracaso terapéutico no permitió asociar este resultado con la existencia de co-morbilidad (ya sea en general o en forma individual para neoplasia, insuficiencia renal o diálisis, por su frecuencia), cirugía en los últimos 12 meses, la edad (mayor o menor de 65 años), puntua- ción APACHE II (0-19 versus > 19), presencia de múltiples sitios de infección, diálisis al inicio del tratamiento, oportunidad de tratamiento (antes o después de las 48 horas del diagnóstico) o al uso de tratamiento combinado ( $p>0,05$ por prueba bilateral de Fisher). Tampoco la recepción de dosis subóptima de colistín por kilo de peso apareció ligada a fracaso terapéutico, análisis efectuado con diferentes puntos de corte $\leq 3$ ó $\leq 4 \mathrm{mg} / \mathrm{kg} /$ día ( $\mathrm{p}>0,5$ por prueba bilateral de Fisher).

Los fracasos sí se asociaron significativamente al tratamiento de pacientes con neumonía, con o sin VM $(\mathrm{p}=0,04)$ (Tabla 4). En presencia de neumonía, sólo $27,3 \%$ presentó una respuesta favorable al tratamiento con colistín. En ausencia de neumonía, este porcentaje llegó a 69,2\%. El tratamiento combinado de colistín con carbapenémicos, aminoglucósidos o rifampicina no se asoció a una mejor respuesta terapéutica.

\begin{tabular}{|lccc|}
\hline \multicolumn{4}{|c|}{ Tabla 4. Respuesta al tratamiento y su asociación con neumonía } \\
\hline Neumonía & $\begin{array}{c}\text { Fracaso } \\
\mathbf{n}(\mathbf{\%})\end{array}$ & $\begin{array}{c}\text { Respuesta al tratamiento } \\
\text { Favorable }\end{array}$ & $\begin{array}{c}\text { Total } \\
\mathbf{n}(\%)\end{array}$ \\
\hline Presente & $8(72,7)$ & $3(27,3)$ & $11(100)$ \\
\hline Ausente & $4(30,8)$ & $9(69,2)$ & $13(100)$ \\
\hline Total & 12 & 12 & 24 \\
\hline$p=0,04$ por prueba de $\chi^{2}$ & & \\
\hline
\end{tabular}

Evolución global. Sólo 45,5\% de los pacientes sobrevivió a la hospitalización $(\mathrm{n}=10)$. Seis de los doce pacientes que fallecieron (50\%), tuvieron su desenlace durante el tratamiento con colistín. Para aquellos pacientes que ingresaron a la UCI, la letalidad en el tramo 0-9 puntos de la puntuación Apache II fue: 1 de 1 (100\%), 6 de $11(54,5 \%)$ en el tramo 10 a 19 puntos, 3 de $4(75 \%)$ en el rango 20 a 29 puntos y 2 de $4(50 \%)$ en el tramo $\geq 30$.

Nefrotoxicidad. Ningún paciente desarrolló nefrotoxicidad de acuerdo con los criterios considerados. En 16 tratamientos $(66,7 \%)$ se utilizaron otros fármacos potencialmente nefrotóxicos en forma concomitante. El valor promedio (DS) de la creatininemia, antes o al inicio del tratamiento con colistín, fue $1,56 \pm 1,33 \mathrm{mg} /$ $\mathrm{dL}$ y de $1,61 \pm 1,03 \mathrm{mg} / \mathrm{dL}$ al finalizar el tratamiento. Otros efectos adversos no fueron evaluados.

\section{Discusión}

La emergencia de bacilos gramnegativos, multi o pan-resistentes y la casi ausencia de nuevas alternati- 
vas terapéuticas, ha obligado al creciente uso de colistín endovenoso en diferentes centros del mundo ${ }^{2,6,7-11}$. En Chile, las primeras experiencias comunicadas datan del año 2004 (XXI Congreso Chileno de Infectología). El Hospital Clínico de la Universidad de Chile aplicó el primer tratamiento en junio de 2005. De acuerdo con nuestro conocimiento, esta sería la primera serie de casos publicada de pacientes tratados con este compuesto en el país.

Colistín (polimixina E), es un compuesto catiónico cíclico que actúa como detergente de la membrana bacteriana y que, a altas concentraciones, tiene un efecto bactericida. Este compuesto no se absorbe por vía oral. Existen dos formulaciones comerciales: colistín sulfato y colistimetato sódico (o colistín metasulfato), correspondiendo la última presentación, a la de uso endovenoso. El colistimetato sódico es, a la vez, menos potente y menos tóxico que el colistín sulfato ${ }^{12}$. La aplicación inicial del producto parenteral llevó a la descripción de importantes efectos adversos nefrotóxicos y neurotóxicos en los años ' 60 y por ello, su uso disminuyó. Luego de su distribución, el producto parenteral es hidrolizado en numerosos derivados incluyendo al colistín sulfato, propiamente tal. Este fenómeno ha impedido un conocimiento acabado de la farmacocinética de este antibacteriano ${ }^{2}$. Colistín posee un espectro de actividad reducido que se limita a algunos bacilos gramnegativos, tales como las enterobacterias y algunos bacilos del grupo no fermentadores. Típicamente, las especies del grupo nemotécnico PPBS son resistentes: Proteus, Providencia, Burkholderia y Serratia ${ }^{2}$.

Este compuesto se ha utilizado por vía endovenosa, en nebulizaciones, en forma intratecal o tópica para tratar diferentes condiciones clínicas, tales como neumonía, bacteriemias, infecciones intra-abdominales, infecciones urinarias, meningitis o ventriculitis, entre otras $^{6-11,13-15}$.

La evaluación de la susceptibilidad al colistín requiere la aplicación de dilución en placa o dilución en caldo. La sensibilidad obtenida por difusión en disco (método Kirby-Bauer) tiene el inconveniente de que un porcentaje de los aislados con CIM elevadas caerán en la zona susceptible ( $\geq 11 \mathrm{~mm}$ ). Los puntos de corte para resistencia han sido elaborados en algunos países europeos pero no en E.U.A. y utilizando colistín sulfato como el compuesto de trabajo. La Sociedad Francesa de Microbiología establece una concentración $>2 \mu \mathrm{g} / \mathrm{mL}$ como punto de corte para definir resistencia (susceptible $\leq 2 \mu \mathrm{g} / \mathrm{mL}$ ). En el Reino Unido este criterio es $\geq 8 \mu \mathrm{g} / \mathrm{mL}$ (susceptible $\leq 4 \mu \mathrm{g} / \mathrm{mL}){ }^{2}$ Nuestra institución ha incorporado el método E-test para evaluar la susceptibilidad de los aislados ante colistín, un método que permite contar con un valor de CIM y de más fácil aplicación asistencial que la microdilución en caldo $^{1}$. La estrategia por E-test ha sido validada con un alto grado de reproducibilidad y concordancia, aunque con limitaciones en valores extremos ${ }^{1}$.

Que la totalidad de los tratamientos con colistín haya involucrado aislados de $P$. aeruginosa o $A$. baumannii, no es discordante con la literatura científica sobre el uso de este compuesto, ya que son precisamente estas especies las que concentran un perfil de pan-resistencia ${ }^{2,6-11}$. Destacan en estos resultados la frecuente ocurrencia de múltiples sitios de infección (58,3\%) y la asociación significativa de $A$. baumannii con múltiples sitios de infección.

Una respuesta favorable fue observada en $50 \%$ de los casos, cifra inferior al $74 \%$ reportado por Michalopoulos y cols, o al 73\% de Markou y cols, en pacientes de $\mathrm{UCI}^{6,11}$. De la misma manera, las cifras son algo inferiores al 57\% señalado por Garnacho-Montero y cols, en pacientes con NAVM o al 58\% reportado por Levin y cols, para infecciones nosocomiales ${ }^{8,9}$. En un reporte previo, Beltrán y cols, describieron una tasa de respuesta favorable en $64,3 \%$ de 14 cursos de terapia, predominantemente en pacientes con neumonía, en dos unidades de Cuidados Intensivos (Libro de resúmenes, XXI Congreso Chileno de Infectología, 2004, Viña del Mar, Chile, CO-68). Las diferencias pueden ser explicadas por la gravedad de los pacientes incluidos, la infección bajo tratamiento, la oportunidad en el inicio del esquema, la dosis utilizada, el uso de antimicrobianos concomitantes con posible efecto sinérgico u otros factores. Por ejemplo, nuestros datos permitieron asociar significativamente una menor probabilidad de respuesta favorable en caso de neumonía $(27 \%)$ al igual que los datos sugeridos por Levin y cols, donde sólo $25 \%$ de los cursos de tratamiento en esta condición estuvieron asociados a una buena respuesta9 ${ }^{9}$. El reducido número de tratamientos impidió encontrar otras asociaciones significativas.

El bajo porcentaje de respuestas favorables observado en nuestro trabajo podría estar ligado a múltiples factores; por ejemplo, al uso de dosis relativamente bajas para lograr un efecto terapéutico. La fórmula farmacéutica disponible en Chile es, en general, de origen inglés (Forest Laboratorios, Kent) y contiene $80 \mathrm{mg}$ de colistimetato sódico por vial, equivalente a 33,3 mg de colistín sulfato, el principio activo. La utilización habitual de un frasco cada 8 horas no permite alcanzar las dosis recomendadas por kilo de peso que se proponen en el Reino Unido. En los pacientes sin falla renal en nuestra serie, el promedio diario de dosis utilizado fue de $3,24 \mathrm{mg} / \mathrm{kg}$, inferior al rango 4 a $6 \mathrm{mg} / \mathrm{kg}$ propuesto en ese país ${ }^{16,17}$. El no alcanzar una dosis mínima, limita el efecto terapéutico, ya que no permite un efecto bactericida concentración dependiente ${ }^{2,12}$. 
Las dosis utilizadas en nuestros pacientes podrían explicar la relativa baja tasa terapéutica obtenida, la persistencia del microorganismo en ciertos casos y la aparición de resistencia en algunos aislados. Si en Chile se tuviera disponible la presentación estadounidense, las dosis podrían ajustarse entre 2 y $5 \mathrm{mg} / \mathrm{kg} /$ día, ya que la presentación de ese país indica los $\mathrm{mg}$ de colistín sulfato disponibles en el frasco (independiente al hecho de que venga como colistimetato sódico) y, además, el envase trae $150 \mathrm{mg}$ del compuesto base $\mathrm{e}^{16,17}$. Matthew Falagas, un experto en el área, propone que para evitar esta confusión es mejor utilizar una dosificación basada en unidades internacionales y recomienda una dosis de 50.000 a $75.000 \mathrm{UI} / \mathrm{kg} /$ día en tres dosis en pacientes con función renal normal ${ }^{16}$. Él y otros autores griegos utilizan habitualmente tres millones de UI cada ocho horas; el triple de la dosis utilizada en nuestros pacientes sin falla renal ${ }^{6,11}$. Las tasas de respuesta en sus trabajos bordean el $70 \% \%^{6,11,18}$. Sin embargo, explorar la importancia de las dosis de colistín o la duración del tratamiento a través de series de casos que difieren en cuanto al tipo de pacientes e infecciones, los agentes involucrados, su gravedad o el uso de terapias combinadas, es una tarea difícil y especulativa.

Un segundo factor podría estar ligado a las bajas concentraciones tisulares en la pleura o en el parénquima pulmonar reportadas para este compuesto (al igual que en hueso y SNC) y ello podría explicar, a priori, una mayor tasa de fracaso terapéutico para infecciones pulmonares ${ }^{12,19}$. No obstante, los datos farmacocinéticos sobre este antimicrobiano recién comienzan a ser delineados, en parte, debido a las dificultades para analizar el compuesto activo en diferentes compartimentos $^{2}$. La existencia de cepas resistentes (con excepción de un caso) puede ser relativamente descartada como factor de fracaso terapéutico en nuestra serie, ya que la frecuencia de este fenómeno fue baja en las cepas disponibles para estudio (9\%) y la cepa resistente fue detectada sólo en agosto de 2006, hacia el cierre del período en estudio.

El uso de una terapia dirigida por los resultados de los cultivos y no sobre bases empíricas, puede haber limitado el éxito terapéutico. Esta estrategia crea, necesariamente, una demora que perjudica al paciente, ya que no cubre en los momentos iniciales a los microorganismos involucrados ${ }^{20}$. No obstante, por ahora el uso empírico de colistín en todos los casos de infecciones nosocomiales en pacientes de unidades intensivas es inpresentable, debido al limitado éxito terapéutico observado y a las grandes dificultades logísticas que implica importar un medicamento no disponible comercialmente en Chile.

La respuesta microbiológica no fue óptima en esta serie de casos, ya que en aquellos cursos donde fue posible evaluarla, la persistencia y no la erradicación del agente fue el resultado más frecuente. La persistencia podría estar ligada a un efecto bacteriostático más que bactericida para este compuesto con las dosis utilizadas (vide supra) o a la participación de biopolímeros en los tubos endotraqueales de los pacientes intubados con neumonía, la infección más frecuentemente tratada. La persistencia del agente explicó tres de las cinco recaídas de la infección observadas en la serie.

Estudios in vitro han demostrado que las combinaciones de compuestos carbapenémicos con aminoglucósidos, polimixinas y/o rifampicina permiten, en ocasiones, una acción sinérgica en curvas de cinética de muerte bacteriana sobre aislados de A. baumannii. Ello ocurre a pesar de que las cepas sean resistentes a los carbapenémicos o rifampicina ${ }^{4,5}$. Las implicancias de esta estrategia han sido exploradas en un modelo animal de neumonía, demostrando una mayor reducción en la carga microbiana en el tejido pulmonar en ciertas combinaciones de antimicrobianos ${ }^{5}$. Por ejemplo, las combinaciones de imipenem con tobramicina fueron las más eficaces en casos de cepas con resistencia de baja magnitud a imipenem pero con susceptibilidad intermedia a tobramicina. En caso de cepas con alto nivel de resistencia a imipenem, la combinación de este compuesto con rifampicina resultó más ventajo$\mathrm{sa}^{5}$. Sin embargo, la combinación de rifampicina con colistín también permitió una reducción del recuento bacteriano pulmonar en estas cepas altamente resistentes, aunque de menor magnitud a lo logrado por las combinaciones de carbapenémicos con tobramicina o rifampicina. Debido a estos antecedentes, nuestro grupo tenía expectativas fundadas para que una respuesta favorable estuviera asociada al uso combinado de colistín con amikacina, imipenem o rifampicina. Los datos observados refutaron esta expectativa, aunque se debe considerar que el número de pacientes que no recibió terapia combinada fue bajo $(<20 \%)$ y que no hubo una randomización al comienzo del tratamiento. El uso de terapias combinadas junto con colistín $\mathrm{u}$ otras polimixinas, ha sido una constante en la literatura científica reciente, pero no ha sido testeada en estudios de tipo caso-control ${ }^{21,22}$. Por ejemplo, en una serie de 14 pacientes tratados con colistín y rifampicina, Petrosillo y cols, describen una respuesta favorable en $50 \%$ de casos de neumonía asociada a VM, algunos de ellos tratados, además, con sulbactam/ampicilina ${ }^{22}$. Aún se requieren mayores estudios para aclarar esta posible ventaja terapéutica.

De acuerdo con los criterios utilizados, ningún paciente presentó nefrotoxicidad asociada al uso de colistín. Ello, a pesar de que en dos tercios de los casos se utilizaron otros potenciales nefrotóxicos en 
forma concomitante. La ausencia de este tipo de reacción adversa es concordante con las publicaciones más recientes que señalan bajas o nulas frecuencias de toxicidad ${ }^{23}$. En las primeras décadas de uso (19601970), las frecuencias de nefrotoxicidad superaban el $20 \%$. Luego de la reintroducción del colistín endovenoso, hacia 1995, las cifras de esta complicación han oscilado entre 0 y $10 \%$, en general, con numerosas experiencias sin esta adversidad ${ }^{23}$. Las razones de este cambio son multifactoriales y parecen estar ligadas a un mejor manejo de los balances hidroelectrolíticos en unidades de cuidados intensivos, a las precauciones en el uso de otros fármacos nefrotóxicos $\mathrm{y}$, posiblemente, a una mejor purificación del compuesto. En caso de ocurrencia, la nefrotoxicidad por colistín es, en la mayor parte de los casos, reversible en un plazo de varias semanas ( 3 a 9). Se manifiesta, principalmente, como insuficiencia renal, es de baja magnitud, dosis dependiente y rara vez requiere apoyo dialítico. El mecanismo de daño está asociado a un cambio en la permeabilidad de membrana ${ }^{23}$. La neurotoxicidad, expresada en forma de parestesias, bloqueo neuromuscular o apneas, fue considerada como la segunda reacción adversa en orden de importancia. Sin embargo, no se han reportado casos con este tipo de problemas desde la reintroducción de colistín, incluso a pesar de una búsqueda activa ${ }^{8,23}$.

Este trabajo tiene varias limitaciones entre las que destaca su diseño metodológico de tipo serie de casos clínicos. Desafortunadamente, todas las experiencias publicadas hasta ahora han tenido esta característica y no se cuenta con estudios randomizados. Un estudio aleatorio comparativo es de difícil ejecución, debido a que no se cuenta con muchas alternativas activas contra estos bacilos pan-resistentes. Una de estas posibilidades, es el compuesto tigeciclina, de reciente introducción en nuestro medio, pero que, lamentablemente, no tiene actividad contra $P$. aeruginos $a^{24}$.

Las principales conclusiones de este trabajo indican que colistín endovenoso es un compuesto seguro en el tratamiento de diversas infecciones asociadas a microorganismos multi o pan-resistentes y que su eficacia es subóptima, especialmente, en pacientes con neumonía.

\section{Resumen}

La emergencia de bacilos gramnegativos pan-resistentes ha obligado a la reutilización progresiva de colistín. Objetivo: Describir la experiencia clínica con este compuesto. Metodología: Se efectuó un análisis retrospectivo de todos los tratamientos con colistín endovenoso administrados por más de 48 horas, analizando datos clínicos, microbiológicos, la respuesta terapéutica y evolución hasta el egreso. Resultados: Se aplicaron 24 tratamientos entre junio de 2005 y septiembre de 2006. Colistín endovenoso fue utilizado en eventos de neumonía asociada a VM ( $\mathrm{n}=10 ; 41,7 \%)$, colecciones o abscesos $(12,5 \%)$, bacteriemias, neumonía no asociada a VM e infección urinaria $(4,2 \%$ cada una, respectivamente). El tratamiento fue iniciado en promedio a 3,2 $( \pm 2,85)$ días desde el diagnóstico de infección. Todos los pacientes tenían infecciones por Pseudomonas aeruginosa o Acinetobacter baumannii. Se evaluó la susceptibilidad por E-test en once aislados $\left(\mathrm{CIM}_{90} 3,6 \mu \mathrm{g} / \mathrm{mL}\right.$, rango 0,38 a $\left.4 \mu \mathrm{g} / \mathrm{mL}\right)$. Una cepa $(9 \%)$ presentó resistencia. Se observó una respuesta favorable en $50 \%$ de los casos $(n=12)$ con recaída en cinco de estos casos $(41,7 \%)$. El único factor asociado a fracaso fue la presencia de neumonía $(p=0,04)$. Se observó erradicación en ocho casos $(33,3 \%)$ y persistencia en once $(45,8 \%)$. En cinco casos el resultado microbiológico no fue evaluable. Sobrevivió a la hospitalización $45,5 \%$ de los pacientes $(\mathrm{n}=10)$. No se observó nefrotoxicidad. Conclusiones: Colistín endovenoso es un compuesto seguro para el tratamiento de infecciones por bacilos gramnegativos pan-resistentes. Sin embargo, su eficacia terapéutica es limitada, especialmente, entre aquellos pacientes tratados por neumonía.

\section{Referencias}

1.- Arroyo L A, García-Curiel A, PachónIbáñez M E, Llanos A C, Ruiz M. Reliability of the E-test method for detection of colistin resistance in clinical isolates of Acinetobacter baumannii. J Clin Microbiol 2005; 43: 903-5.

2.- Li J, Nation R L, Milne R W, Turnidge J D, Coulthard K. Evaluation of colistin as an agent against multi-resistant gram-negative bacteria. Int J Antimicrob Agents 2005; 25: 11-25.
3.- Knaus W A, Draper E A, Wagner D P, Zimmerman J E. APACHE II: a severity of disease classification system. Crit Care Med 1985; 13: 818-29.

4.- Yoon J, Urban C, Tercian C, Mariano N, Rahal J J. In vitro double and triple synergistic activities of polymyxin B, imipenem, and rifampin against multidrugresistant Acinetobacter baumannii. Antimicrob Agents Chemother 2004; 48: 753-7.

5.- Montero A, Ariza J, Corbella X, Doménech A, Cabellos C, Ayats J, et al. Antibiotic combinations for serious infections caused by carbapenem-resistant Acinetobacter baumannii in a mouse pneumonia model. J Antimicrob Chemother 2004; 54: 1085-91.

6.- Michalopoulos A S, Tsiodras S, Rellos K, Mentzelopoulos S, Falagas M E. Colistin treatment in patients with ICU-acquired infections caused by multiresistant Gramnegative bacteria: the renaissance of an old antibiotic. Clin Microbiol Infect 2005; 11 : 115-21.

7.- Berlana D, Llop J M, Fort E, Badia M B, Jódar R. Use of colistin in the treatment of 
multiple-drug-resistant gram-negative infections. Am J Health-Sys Pharm 2005; 62: 39-47.

8.- Garnacho-Montero J, Ortiz-Leyba C, Jiménez-Jiménez FJ, Barrero-Almodóvar A E, García-Garmendia J L, BernabeuWittell $\mathrm{M}$, et al. Treatment of multidrugresistant Acinetobacter baumannii ventilator-associated pneumonia (VAP) with intravenous colistin: A comparison with imipenem-susceptible VAP. Clin Infect Dis 2003; 36: 1111-8.

9.- Levin A S, Barone A A, Penço J, Santos M V, Marinho I S, Arruda E A G, et al. Intravenous colistin as therapy of nosocomial infections caused by multidrugresistant Pseudomonas aeruginosa and Acinetobacter baumannii. Clin Infect Dis 1999; 28: 1008-11.

10.- Linden P K, Kusne S, Coley K, Fontes P, Kramer D J, Paterson D. Use of parenteral colistin for the treatment of serious infections due to antimicrobial-resistant Pseudomonas aeruginosa. Clin Infect Dis 2003; 37: e154-60.

11.- Markou N, Apostolakos H, Koumoudiou C, Athanasiou M, Koutsouku A, Alamanos I, et al. Intravenous colistin in the treatment of sepsis from multi-resistant gram-negative bacilli in critically ill patients. Crit Care 2003; 7: R78-83

12.- Falagas M E, Kasiakou S K. Colistin: the revival of polymyxins for the management of multidrug-resistant gram-negative bacterial infections. Clin Infect Dis 2005; 40: $1333-41$.
13.- Kwa A L H, Lo C S, Low J G H, Kurup A, Tam V H. Nebulized colistin in the treatment of pneumonia due to multidrugresistant Acinetobacter baumannii and Pseudomonas aeruginosa. Clin Infect Dis 2005; 41: 754-7.

14.- Jiménez-Mejías M E, Pichardo-Guerrero C, Márquez-Rivas F J, Martín-Lozano D, Prados T, Pachón J. Cerebrospinal fluid penetration and pharmacokinetic/ pharmacodynamic parameters of intravenously administered colistin in a case of multidrug-resistant Acinetobacter baumannii meningitis. Eur J Clin Microbiol Infect Dis 2002; 21: 212-4.

15.- Fernández-Viladrich $P$, Corbella $X$, Corral F, Tubau F, Mateu A. Successful treatment of ventriculitis due to carbapenem-resistant Acinetobacter baumannii with intraventricular colistin sulfomethate sodium. Clin Infect Dis 1999; 28: 916-7.

16.- Falagas M E, Kasiakou S K, Tsiodras S, Michalopoulos A. The use of intravenous and aerosolized polymyxins for the treatment of infections in critically ill patients: a review of the recent literature. Clin Med Res 2006; 4: 138-46.

17.- Falagas M E, Kasiakou S K. Use of internacional units when doping colistin Hill help decrease confusion related to various formulations of the drug around the world. Antimicrob Agents Chemother 2006; 50: 2274-5.

18.- Kasiokou S K, Michalopoulos A, Soteriades E S, Samonis G, Sermaides G J, Falagas M E. Combination therapy with intravenous colistin for management of infections due to multidrug-resistant Gramnegative bacteria in patients without cystic fibrosis. Antimicrob Agents Chemother 2005; 49: 3136-46.

19.- Evans M E, Feola D J, Rapp R R. Polymixin B sulfate and colistin: Old antibiotics for emerging multiresistant Gram negative bacteria. Ann Pharmacother 1999; 33: 960-7.

20.- Celis R, Torres A, Gatell J M, Almela M, Rodríguez-Roisin R, Agusti-Vidal A. Nosocomial pneumonia. A multivariate analysis of risk and prognosis. Chest 1988; 93: 318-24.

21.- Sobieszczyk M E, Furuya E Y, Hay C M, Pancholi P, Della-Latta P, Hammer S M, et al. Combination therapy with polymyxin $\mathrm{B}$ for the treatment of multidrug-resistant gram-negative respiratory tract infections. J Antimicrob Chemother 2004; 54: 566-9.

22.- Petrosillo N, Chinello P, Proietti N F, Cecchini L, Masala L, Franchi C, et al. Combined colistin and rifampicin therapy for carbapenem-resistant Acinetobacter baumannii infections: clinical outcome and adverse events. Clin Microbiol Infect 2005; 11: $682-3$.

23.- Falagas M E, Kasiakou S K. Toxicity of polymyxins: A systematic review of the evidence from old and recent studies. Crit Care 2006; 10: R27 (doi:10.1186/cc3995).

24.- Livermore D M. Tigecycline: What is it, and where should it be used? J Antimicrob Chemother 2005; 56: 611-4. 